\title{
Shear failures in cantilevered reinforced concrete slab-strips without transverse reinforcement
}

\author{
Christian Svarre ${ }^{1}$, Jakob Fisker ${ }^{2}$, Lars Hagsten ${ }^{3}$ \\ Department of Engineering, Aarhus University, Aarhus, Denmark \\ E-mail: 2jafi@ase.au.dk (corresponding author)
}

\begin{abstract}
Design of slabs without shear reinforcement is, in practice, based mainly on empirical codified methods, derived on the basis of a large number of tests. However, the vast majority of these tests involves simply supported beams, with substantial amounts of longitudinal reinforcement, subjected to three- or four point bending. This paper presents the results of a significant experimental programme comprising eighteen simply supported - cantilevered slabstrips without stirrup reinforcement, and with a light amount of longitudinal reinforcement. Stirrups in the surrounding parts founded a shear critical region located in the hogging region of the simple span. All beams failed in shear within this shear critical region, the slenderness of which was fixed for all the beams. The influence of the concrete strength, which is of special interest in relation to lightly reinforced members, was investigated by varying the concrete strength systematically within the test series. The influence of the concrete strength and mix with respect to crack roughness was further studied using a large number of concrete cores prepared with coloured epoxy. The cores were all extracted from various zones containing critical and "non-critical" shear cracks. Photogrammetric measurements (digital image correlation) and optical fiber measurements were conducted in the shear critical region on all tested specimens, and detailed analysis on the propagation and kinematics of critical cracks are presented.
\end{abstract}

Keywords: shear, concrete structures, experimental observations, photogrammetry.

\section{Introduction}

Shear failure represent a very critical mode of structural failure; even more so for members without transverse reinforcement due to the extreme brittleness, and thus lack of prior warning. This latter type of structural members are most often encountered in the case of slabs, be they statically determinate or indeterminate. Design models used in daily practice in regards to shear capacity are empirical, and derived on the basis of a large number of tests $e . g$. (Reineck, Kuchma, Kim, \& Marx, 2003) and (Collins, Bentz, \& Sherwood, 2008). Unfortunately, the majority of tests included in these databases, and thus the empirical core of the design models, do not reflect the actual conditions met in practice concerning e.g. statical conditions as well as member properties such as the amount of longitudinal reinforcement and slenderness. Pioneering work by e.g. Leonhardt \& Walther (Leonhardt \& Walther, 1962) and others revealed the favorable influence of strut and tie action present in the region near direct supports, which for obvious reasons is not present in statically indeterminate slabs near the point of contra-flexure. In addition, the development of cracks in the hogging region of slender, multi-span slabs appears to be somewhat different to what is typically observed in the case of the simply supported beams traditionally used for testing; this may also be of influence in regards to the accompanying shear capacity and failure mechanism. Examination of existing databases also reveal that slenderness and longitudinal reinforcement-ratio of the vast majority of all tested beams are, in fact, not representative for slab members in practice, often reaching high level of flexural utilization, and thus greater crack-widths.

The aim of the experimental programme presented in the following, is to replicate conditions, commonly encountered in practise; lightly reinforced concrete slabs without transverse reinforcement, spanning across multiple spans. This was archived by constructing a test setup containing a cantilever beam subjected to two point loads - one at the cantilever end, and one in the span. The test setup, furthermore, allowed the test members to be designed with a shear slenderness closer to what is typically observed in practice.

The influence of the concrete strength was of special interest in the experimental investigations. In general, when increasing the strength of the concrete, the shear capacity is increased, which is also reflected in most design models. However, there seems to be a certain level of uncertainty concerning experimental evidence in regards to the influence of this parameter when the strength is increased beyond, say $50 \mathrm{MPa}$. Some investigations seems to suggest that the

(C) 2019 Authors. Published by VGTU Press. This is an open-access article distributed under the terms of the Creative Commons Attribution (http://creativecommons.org/licenses/by/4.0/) License, which permits unrestricted use, distribution, and reproduction in any medium, provided the original author and source are credited. 
shear strength remains approximately constant when further increasing the concrete strength (Angelakos, Bentz, \& Collins, 2001; Podgorniak-Stanik, 1998) while in other investigations continued slight improvements are observed. Finally, and in practice more importantly, there are investigations in which an actual drop has been observed when entering the lower range of high-strength concrete (Pedersen, Fisker, \& Nielsen, 2015). Unfortunately, it is difficult to compare such investigations directly owing the level of scatter observed in concrete tests, in combination with a mismatch of other important parameters (e.g. slenderness, reinforcement-ratio etc.). However, there is a growing consensus, and some experimental evidence, that crack surfaces in higher strength concrete are less rough when compared to lower strength concrete, due to cracks more frequently propagating through the relatively weaker aggregates. The discprencies observed with respect to the shear capacity on a member-level is, on this basis, often explained with reference to increase of the brittleness in general, and more specifically, a reduction of the ability to transfer forces across cracks via aggregate interlock and residual tensile stresses, e.g. (Walraven \& Stroband, 1994) and (Sherwood, 2008). This is, unfortunately, not reflected in current codes for practice.

\section{Experimental programme}

\section{Test-setup, test specimens and test procedure}

The experimental programme comprised a total of eighteen beams subdivided into three groups; G1, G2 and G3, in accordance with Table 1. All beams had a total length of $7400 \mathrm{~mm}$ and rectangular cross-sections of dimensions $200 \times 450(b \cdot h)$, see Figure 1a, b, c. For the first group of beams the length of the cantilevered segment was $1700 \mathrm{~mm}$, whereas this length was reduced to $1200 \mathrm{~mm}$ for the second and third group. High-strength reinforcement bars from $S A H$ where used in order to ensure the desired shear failure in combination with a light amount of longitudinal reinforcement, and for all beams equal amounts reinforcements were provided in the top and bottom. The reinforcement ratio differed for the three groups, as illustrated in Figure 1c, with reinforcement ratios $\left(A_{s} /(b \cdot d)\right) 0.94 \%, 0.43 \%$ and $0.62 \%$ for group one, two and three, respectively. The bars were fixed to external steel plates to ensure sufficient anchorage. For group one and three hot-rolled reinforcement were used, with a measured yield strength of 963 and $965 \mathrm{MPa}$ for group one and three, respectively. For group two, on the other hand, the reinforcement was cold-rolled with no distinct yield plateau. The measured average proof stress $f_{y}(0.2 \%$ strain $)$ was $945 \mathrm{MPa}$, and a ratio of 1.23 between the ultimate strength and the yield strength $\left(f_{u} / f_{y}\right)$. Measured stress-strain relations are given in Figure 1d. All eighteen beams were designed to fail in shear in a predefined area (critical region in Figure 1a-b). The length of the critical region was $2.0 \mathrm{~m}$, which approximately equals the distance between the support to the expected point of contraflexure. Failure outside of this region was avoided by the arrangement of sufficient stirrups.

In order to investigate the influence of the concrete strength, the compressive strength was varied within each of the three groups. The measured mean compressive cylinder strength for each beam is listed in Table 1. The local concrete manufacturer Unicon provided the fresh concrete, for which a maximum aggregate size $\left(d_{g}\right)$ of $16 \mathrm{~mm}$ were used.

Concentrated loads were generated using two MTS hydraulic actuators. The main actuator $\left(F_{1}\right)$, cf. Figure 1a, b, was displacement controlled with a piston speed of $0.5 \mathrm{~mm} / \mathrm{min}$ in the first group, $0.25 \mathrm{~mm} / \mathrm{min}$ for second group and $0.15 \mathrm{~mm} / \mathrm{min}$ for beams in group three. The secondary actuator $\left(F_{2}\right)$ was force controlled to a fixed ratio $\left(F_{2} / F_{1}\right)$ of the force generated by the main actuator $\left(F_{1}\right)$. The ratio was fixed to 0.8 for the first group, and 1.15 for the second and third group. Hereby a shear slenderness $(a / d)$ of 5 was obtained for all the beams. The slight variation of the slenderness, as listed in Table 1, is due to the dead-load of the beams.
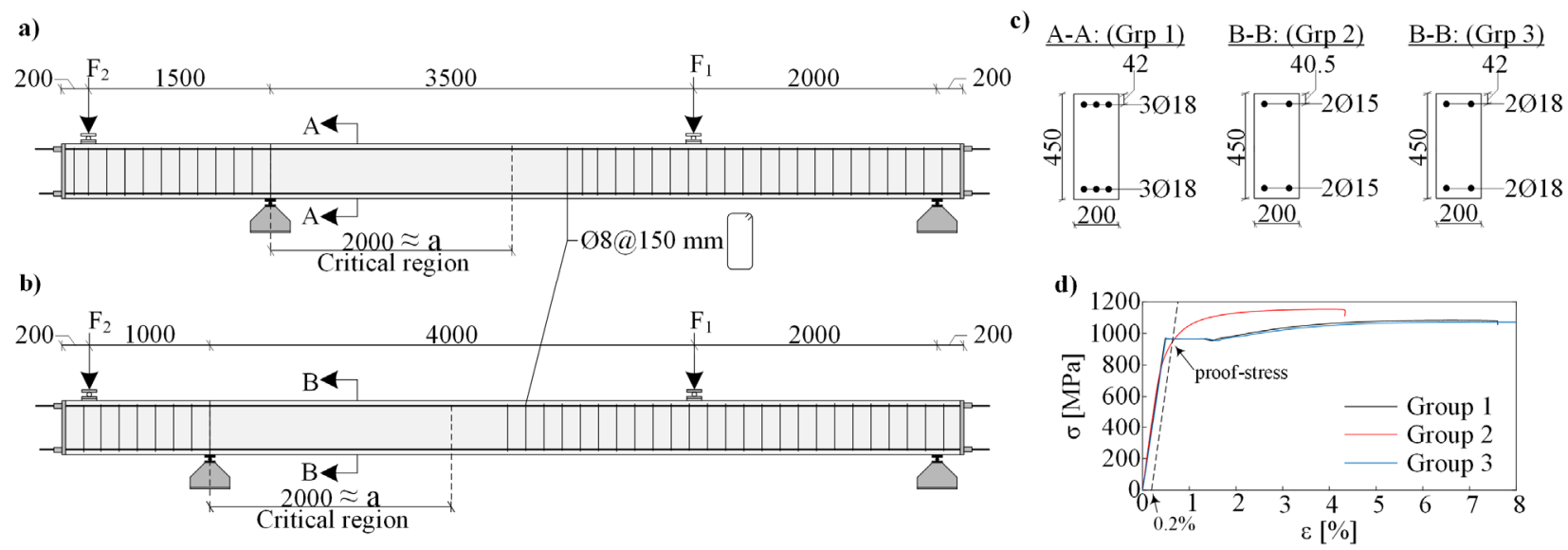

Figure 1. a) Test beams and test setup for group one; b) Test beams and test setup for group two and three; c) Cross-sections for all beams; d) Strain-stress relation for longitudinal reinforcement 


\section{Instrumentation}

Photogrammetric measurements on the surface of the critical region were performed with an ARAMIS 2D Motion and Deformation System and analysed using the associated software GOM Correlate, while LVDT's on the top surface of the beams were used to measure the displacements along the entire length of the beams. Actuator forces and displacements were measured digitally using the control-software MTS TestSuite. All measurements were collected and synchronized using multiple QuantumX data acquisition units.

Fibre optical cables were installed on selected beams in the third group (one for each intended variation of the concrete strength). The fibres were placed a few millimetres on the inside of the longitudinal reinforcement in both the top side and the bottom side of the beams. The optical fibres were thus not mounted directly on the reinforcement, but were embedded in the concrete. The strain-measurements obtained from the fibres thus represents the strain in the concrete. The fibre optical cables had a gauge length of $5 \mathrm{~mm}$ with an overlap of $50 \%$, which, effectively, corresponds to a measurement point per $2.5 \mathrm{~mm}$. Concrete cores were drilled and extracted from the failed specimens at the location of non-critical cracks. This was done in an attempt to study the influence of the concrete strength with respect to crackroughness. The cores were prepared with an epoxy-resin, and the crack pattern was subsequently tracked using an UV-light source.

Table 1. Key experimental results. Internal forces include an assumed deadload equal to $2500 \mathrm{~kg} / \mathrm{m}^{3}$

\begin{tabular}{|c|c|c|c|c|c|c|c|c|c|c|}
\hline & $\begin{array}{c}f_{c . m} \\
{[\mathrm{MPa}]}\end{array}$ & $\begin{array}{c}a \\
{[\mathrm{~m}]}\end{array}$ & $\begin{array}{c}a / d \\
{[-]}\end{array}$ & $\begin{array}{c}F_{1} \\
{[\mathrm{kN}]}\end{array}$ & $\begin{array}{c}V_{L} \\
{[\mathrm{kN}]}\end{array}$ & $\begin{array}{c}V_{R} \\
{[\mathrm{kN}]}\end{array}$ & $\begin{array}{c}M_{L} \\
{[\mathrm{kNm}]}\end{array}$ & $\begin{array}{c}M_{R} \\
{[\mathrm{kNm}]}\end{array}$ & $\begin{array}{c}M_{L} / M_{y} \\
{[-]}\end{array}$ & $\begin{array}{c}X_{c r} / a \\
{[-]}\end{array}$ \\
\hline G1P25-1 & 26.3 & 1.97 & 4.82 & 114.5 & 73.5 & 68.8 & -140.0 & 2.3 & 0.56 & 0.20 \\
\hline G1P25-2 & 26.3 & 1.95 & 4.79 & 101.0 & 65.7 & 61.0 & -123.8 & 2.8 & 0.50 & 0.42 \\
\hline G1P50-1 & 52.4 & 1.97 & 4.82 & 115.7 & 74.2 & 69.5 & -141.5 & 2.3 & 0.52 & 0.65 \\
\hline G1P50-2 & 52.4 & 1.98 & 4.85 & 135.0 & 85.4 & 80.8 & -164.6 & 1.6 & 0.60 & 0.43 \\
\hline G2P25-1 & 31.9 & 2.03 & 4.96 & 102.3 & 60.9 & 56.2 & -118.8 & -1.7 & 0.93 & 0.25 \\
\hline G2P25-2 & 31.9 & 2.05 & 5.00 & 116.4 & 68.3 & 63.6 & -135.0 & -3.1 & 1.05 & 0.27 \\
\hline G2P25-3 & 31.9 & 2.05 & 5.01 & 120.3 & 70.4 & 65.7 & -139.5 & -3.5 & 1.09 & 0.68 \\
\hline G2P50-1 & 55.3 & 2.05 & 5.06 & 116.4 & 68.3 & 63.6 & -135.0 & -3.1 & 1.04 & 0.35 \\
\hline G2P50-2 & 55.3 & 2.06 & 5.08 & 122.0 & 71.2 & 66.6 & -141.5 & -3.6 & 1.09 & 0.23 \\
\hline G2P50-3 & 55.3 & 2.05 & 5.07 & 118.7 & 69.5 & 64.8 & -137.7 & -3.3 & 1.06 & 0.23 \\
\hline G3P20-1 & 27.1 & 2.04 & 5.00 & 112.1 & 66.0 & 61.4 & -130.1 & -2.6 & 0.73 & 0.22 \\
\hline G3P20-2 & 27.1 & 2.06 & 5.04 & 123.2 & 71.9 & 67.2 & -142.8 & -3.8 & 0.80 & 0.44 \\
\hline G3P30-1 & 39.8 & 2.07 & 5.07 & 137.6 & 79.4 & 74.8 & -159.4 & -5.2 & 0.86 & 0.64 \\
\hline G3P30-2 & 39.8 & 2.06 & 5.05 & 126.9 & 73.8 & 69.1 & -147.1 & -4.1 & 0.79 & 0.33 \\
\hline G3P40-1 & 58.1 & 2.08 & 5.10 & 149.0 & 85.4 & 80.8 & -172.5 & -6.3 & 0.91 & 0.27 \\
\hline G3P40-2 & 58.1 & 2.07 & 5.08 & 138.5 & 79.9 & 75.2 & -160.4 & -5.3 & 0.84 & 0.32 \\
\hline G3P50-1 & 62.2 & 2.05 & 5.02 & 117.5 & 68.9 & 64.2 & -136.3 & -3.2 & 0.71 & 0.24 \\
\hline G3P50-2 & 62.2 & 2.06 & 5.06 & 129.7 & 75.3 & 70.6 & -150.3 & -4.4 & 0.79 & 0.28 \\
\hline
\end{tabular}

\section{Results}

All specimens failed in shear in the predefined critical region. The main actuator force and corresponding internal forces at peak-load are listed in Table 1 for each beam. Sectional forces $V_{L}, M_{L}, V_{R}$ and $M_{R}$ refers to the left- and right end-sections of the critical region. For the second group of beams the applied load slightly exceeded the nominal flexural capacity (based on proof-stress). However, it is to be noticed that this group of beams, as mentioned, were provided with cold-rolled reinforcement, and the corresponding load-displacement/rotation diagrams revealed no indication of reinforcement yielding, see Figure $2 b$-d. Likewise, no plastic strain development was observed before failure.

In Figure 2a the measured shear capacities are plotted against the corresponding concrete compressive strength. In the case of group one, a slight increase of the shear capacity is observed when increasing the concrete strength from approximately $26 \mathrm{MPa}$ to $52 \mathrm{MPa}$, amounting to approximately $15 \%$. Likewise, an increase of approximately $20 \%$ is observed in the case of group three, when increasing the concrete strength from approximately $27 \mathrm{MPa}$ to $58.1 \mathrm{MPa}$. The net dependency of the shear capacity with respect to the concrete strength is thus observed to be, more or less, identical for these two groups. In the case of group three, however, a further increase of the concrete strength $\left(f_{c . m}=\right.$ 62.2 $\mathrm{MPa}$ ) revealed a significant and consistent drop of the shear capacity. Finally, and in contrast to group one and 
three, no significant increase of shear capacity is observed when increasing the concrete strength in the case of group two, with the lowest amount of longitudinal reinforcement. The longitudinal reinforcement ratio was observed to have limited influence on the shear capacity, especially between group one and three, where practically no difference is observed.

Figure 3 gives a graphical outline of the observed crack patterns and failure lines for each of the eighteen tested beams. The solid black lines illustrates visible cracks when reaching peak-load, while the solid red line visualizes the observed cracks developed from peak-load to collapse. Finally, the shaded thick line represents the apparent line of failure at collapse. The dark grey region near the bottom side of the beams indicates the height of the plastic compressive zone.

In Table $1, x_{c r}$ refers to the distance from the left support to the point at which the failure line crosses mid height of the beams. In the table $x_{c r}$ is given relatively to the shear span $a$. Examination of Figure 3 and Table 1, reveals no apparent relation between the failure line position $\left(x_{c r}\right)$ and the amount of reinforcement or concrete strength. For the case of group two it can further be observed that the line of failure is located outside any potential plastic hinges.
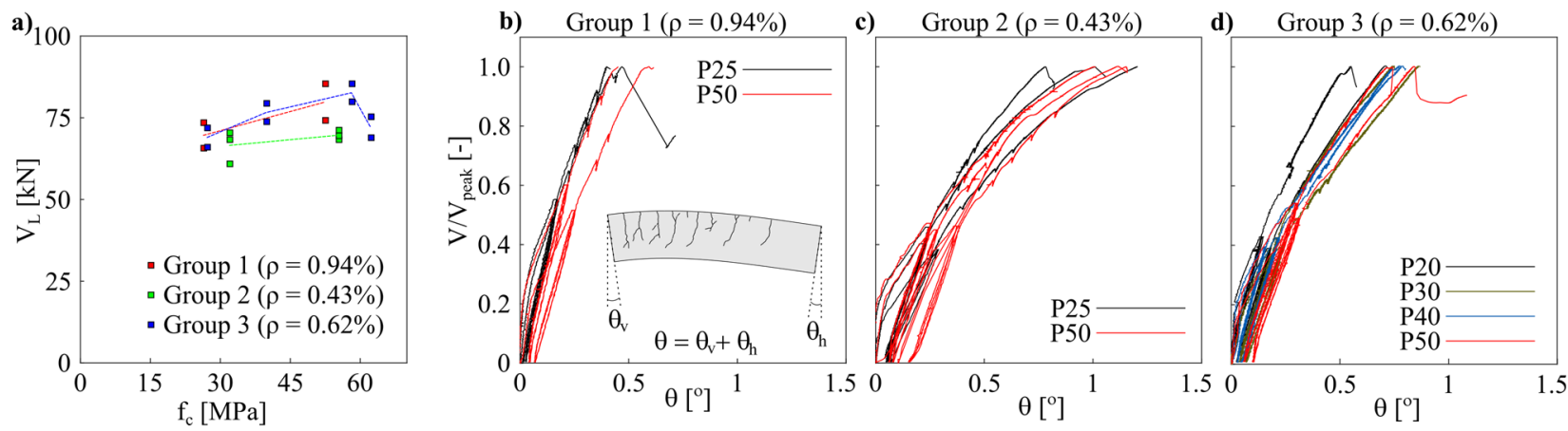

Figure 2. a) Shear-capacities of all beams plotted against the concrete compressive strength; b-d) the applied shear force $\left(V / V_{\text {peak }}\right)$ plotted against the total rotation $(\theta)$ of the end sections of the critical region

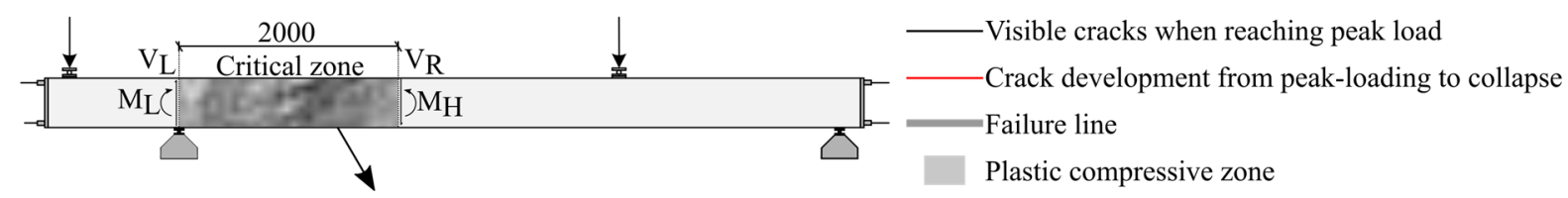

G1P25-1:

G2P25-3:

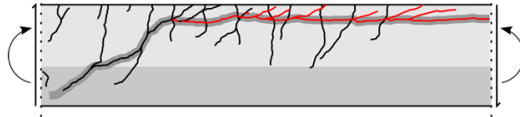

G1P25-2:

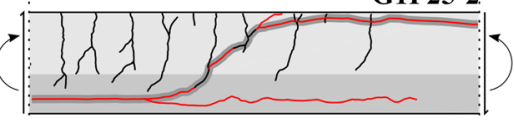

G1P50-1:

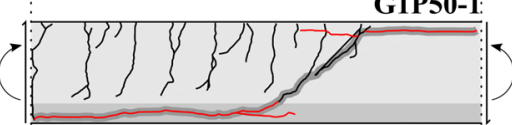

G1P50-2

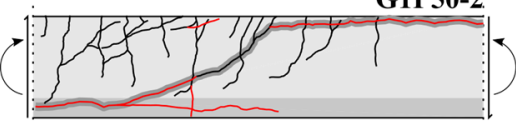

G2P25-1

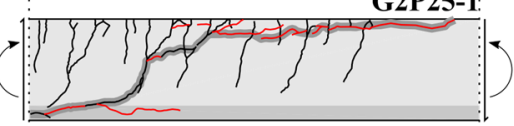

G2P25-2:

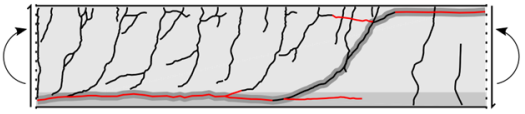

G2P50-1

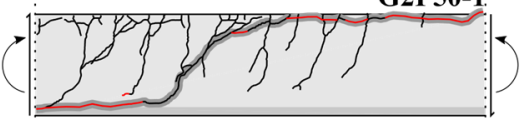

G2P50-2

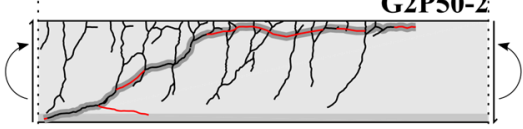

G2P50-3

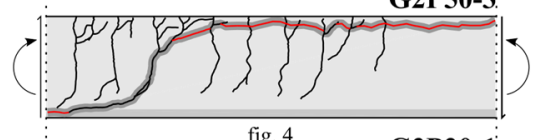

fig. $4 \quad$ G3P20-1

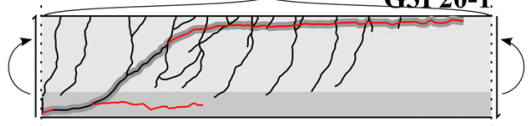

G3P20-2
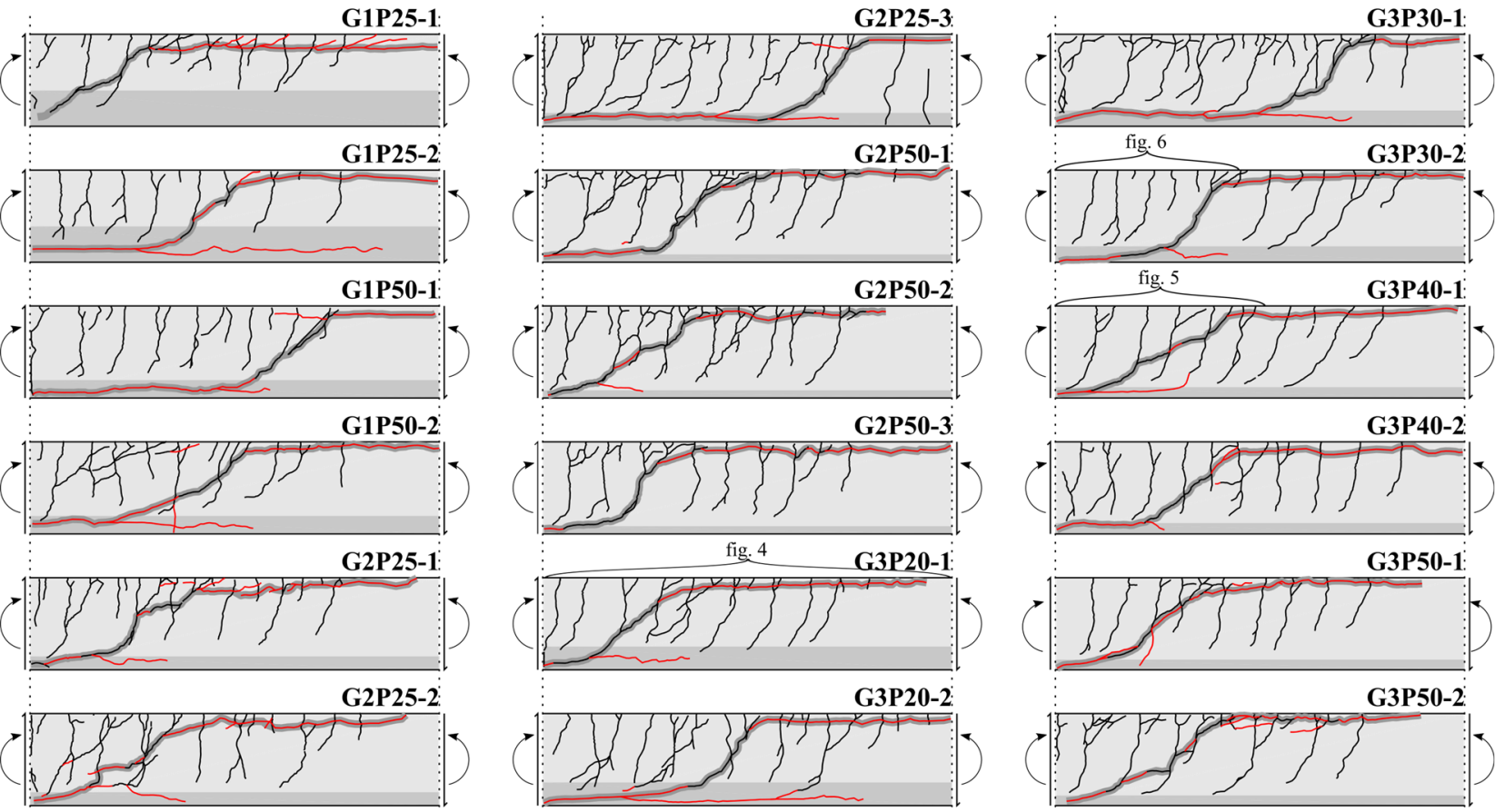

G3P50-2:

Figure 3. Observed crack patterns at peak-load (black line) and after collapse (red line).

The peak internal forces are listed in Table 1 


\section{Behaviour and crack propagation prior to peak}

Figures $2 b-d$ displays the relation between the shear force $\left(V / V_{\text {peak }}\right)$ (relative to the peak-load) and the total rotation $\theta$ of the predefined critical zone for all of the tested beams. As can be seen, the diagrams reveal no information concerning an incipient failure, and thus no warning at all. When comparing the three tested groups of beams the response is seen to become gradually softer as the amount of longitudinal reinforcement is lowered. For groups one and three the relation is approximately bi-linear, although with different stiffness, while the relation tends to be nonlinear for group two, containing the lowest amount of reinforcement.

Figure $4 \mathrm{a}$ illustrates crack displacements in combination with the longitudinal strains in the top and bottom chord of the critical region of beam G3P20-1. The relation between the magnitude of the applied load and the color-code follows from Figure 4b. A similar behaviour was, however, observed for all the beams; in general, mainly vertical cracks developed until reaching a load of approximately $0.8-0.9\left(\mathrm{~V} / \mathrm{V}_{\text {peak }}\right)$, indicating that bending is the governing mode of action dictating the crack development in this range. The first green load stage, represents the stage at which the member departs from this stable progression, and the propagation of potentially critical inclined crack becomes visible. The subsequent green loads-stages until peak-load then refers to stages which represents considerable propagation or development of new cracks, while the last green load stage represents peak-load. Finally, the red load stages refers to the generally short interval between peak-load and collapse. The deformation increment between the first signs of failure to the point of collapse were very small, and it was practically impossible to observe any change of behaviour with the naked eye before the actual collapse.

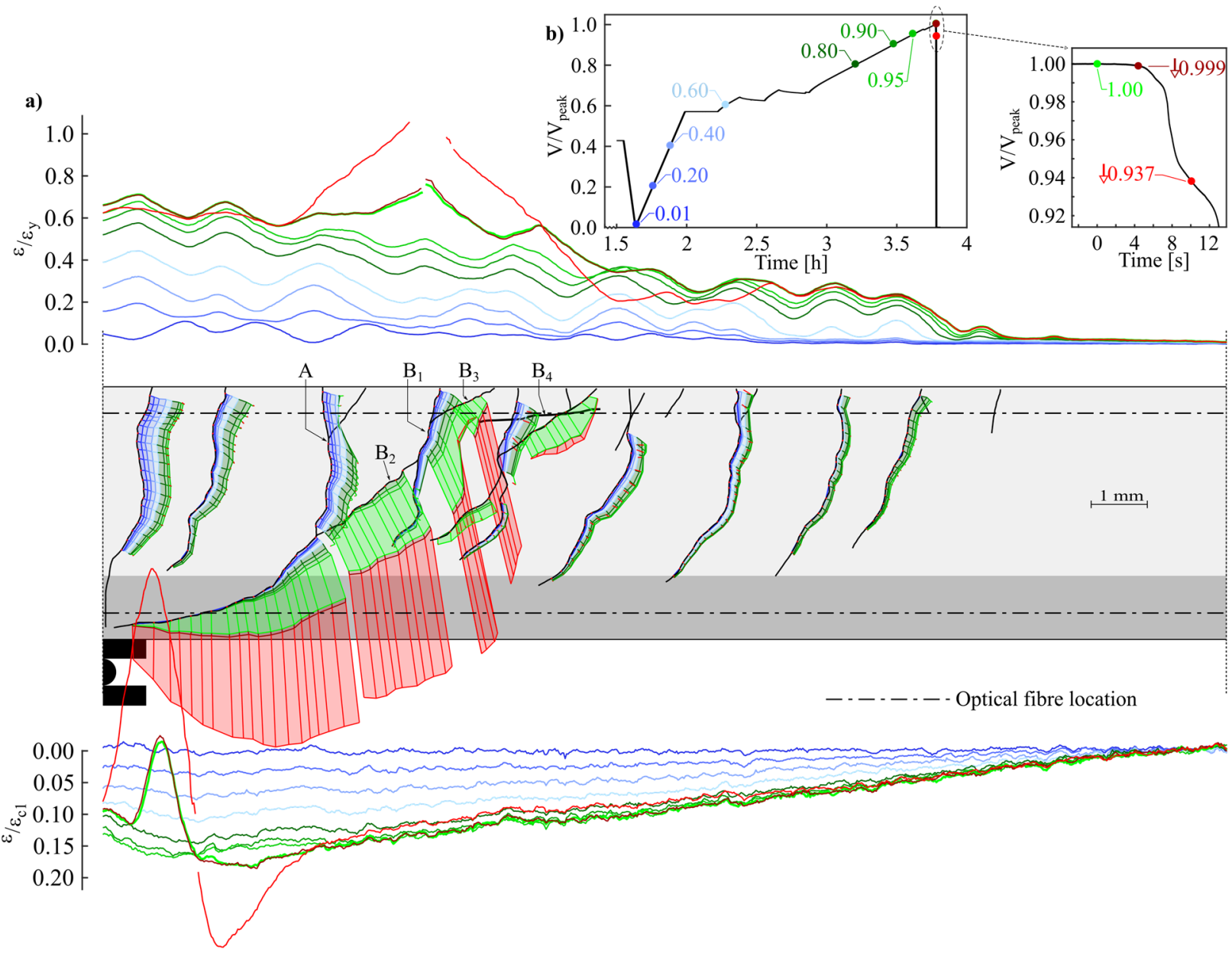

Figure 4. a) Strain measured in the critical region of specimen G3P20-1. $\varepsilon_{c 1}=2.225 \%, \varepsilon_{y}=0.5 \%$ and crack propagation and relative crack displacement at selected load stages; b) Force-time diagram of the loading procedure.

Each coloured dot represent the selected load-stage for the measured strains and crack displacements in plot (a.

In between the blue load-stages the load is increased by a constant increment corresponding to $0.2\left(\mathrm{~V} / \mathrm{V}_{\text {peak }}\right)$ for the considered beam. As can be observed from Figure 4a the corresponding incremental increase with respect to both the longitudinal strains and the crack displacement are found to be more or less constant, manifesting an approximately linear behaviour in this load interval. In fact, in many cases, and also for the considered beam, this linear behaviour lasted into the green load range, despite the emergence or propagation of an inclined and potentially critical crack. 
Furthermore, both strain and crack displacements vary approximately linearly along the length of the critical region underlining the dominating influence of bending. The measured crack displacements can be adequately described by an instantaneous centre of rotation located at the tip of each crack (Olling \& Svarre, 2017). Due to the primarily straight cracks, all measured crack displacements are consequently manifested mainly as crack opening. At later load stages, a more inclined propagation of the primary cracks were observed. This event leads to a new position of the crack tip and thereby also the instantaneous centre of rotation. Consequently, sliding displacements are introduced along the vertical parts of the cracks.

\section{Behaviour and crack propagation during failure}

As mentioned, although the applied load was close to the peak-load, there was in general very little signs or indications that a failure was close by, and the observed crack propagation and/or development of new cracks, which ended up triggering collapse of the specimen, occurred rapidly, and, in some cases, only after peak had been reached. In general, the eventual path of any critical crack or failure line could not be predicted $a$ priori.

The apparent pattern of critical cracks, and more specifically, the path, progression and position of the line of failure differed considerably for the eighteen tested beams. Certain overall characteristics in regards to the mode of failure could, however, be defined, and most beams failed due to a mix of two different failure modes or crack propagation modes.

The first failure mode is referred to as merging of cracks. This failure mode is categorized by the observation that collapse is triggered by the merging of a number of different, mainly newly developed cracks, transforming into a complete failure line. Peak-load is reached just prior to the merging of these cracks, and collapse is triggered by the confluence of the cracks. This mode of failure can be further elaborated using Figure 5, illustrating the pattern of cracks at failure in the case of beam G3P40-1. In this specific case, the primary cracks (e.g. A, $\left.\mathrm{B}_{1}, \mathrm{C}\right)$ were the only cracks developed during the stable "blue loading range", which for the considered beam was concluded at $0.97 \mathrm{~V} / \mathrm{V}_{\text {peak. }}$ The subsequent development of new cracks occurred fairly sudden; the propagation of crack $\mathrm{D}_{1}$ was initiated from crack $\mathrm{B}$ at $0.97 \mathrm{~V} / \mathrm{V}_{\text {peak }}$, and the crack propagated towards crack $\mathrm{A}$. Crack $\mathrm{D}_{1}$ was fully developed and merged with crack $\mathrm{A}$ before reaching $0.99 \mathrm{~V} / \mathrm{V}_{\text {peak. }}$. When this occurred, crack $\mathrm{B}_{2}$ developed instantaneously. Hereafter, all further displacements localized in the newly developed cracks. Crack $\mathrm{D}_{2}$ was fully propagated and merged with crack $\mathrm{C}$ at the time of reaching the peak-load, while crack $\mathrm{D}_{3}$ propagated towards crack $\mathrm{D}_{1}$ between peak-load and collapse. Collapse was triggered just as these two cracks merged, and thus turned into a continuous line of failure, see Figure 3.

The other observed failure mode is referred to as single crack propagation, and this failure mode is characterised by the gradual propagation of a single existing crack deep into the apparent flexural compressive zone, and the failure occurs unaffected by nearby crack development. This mode of failure is very well illustrated by the case of beam G3P30-2. As seen in Figure 6, the crack displacements were linearly increased in each of the primary cracks up to approximately $0.7 \mathrm{~V} / \mathrm{V}_{\text {peak. }}$. Crack $\mathrm{A}_{2}$ and $\mathrm{A}_{3}$ both merged with crack $\mathrm{A}_{1}$ before reaching $0.7 \mathrm{~V} / \mathrm{V}_{\text {peak. }}$. This subsequently resulted in a deactivation of the top part of crack $A_{1}$, in combination with an excessive increase of crack displacements. The collapse was triggered by propagation of the critical crack deep into the compressive zone.
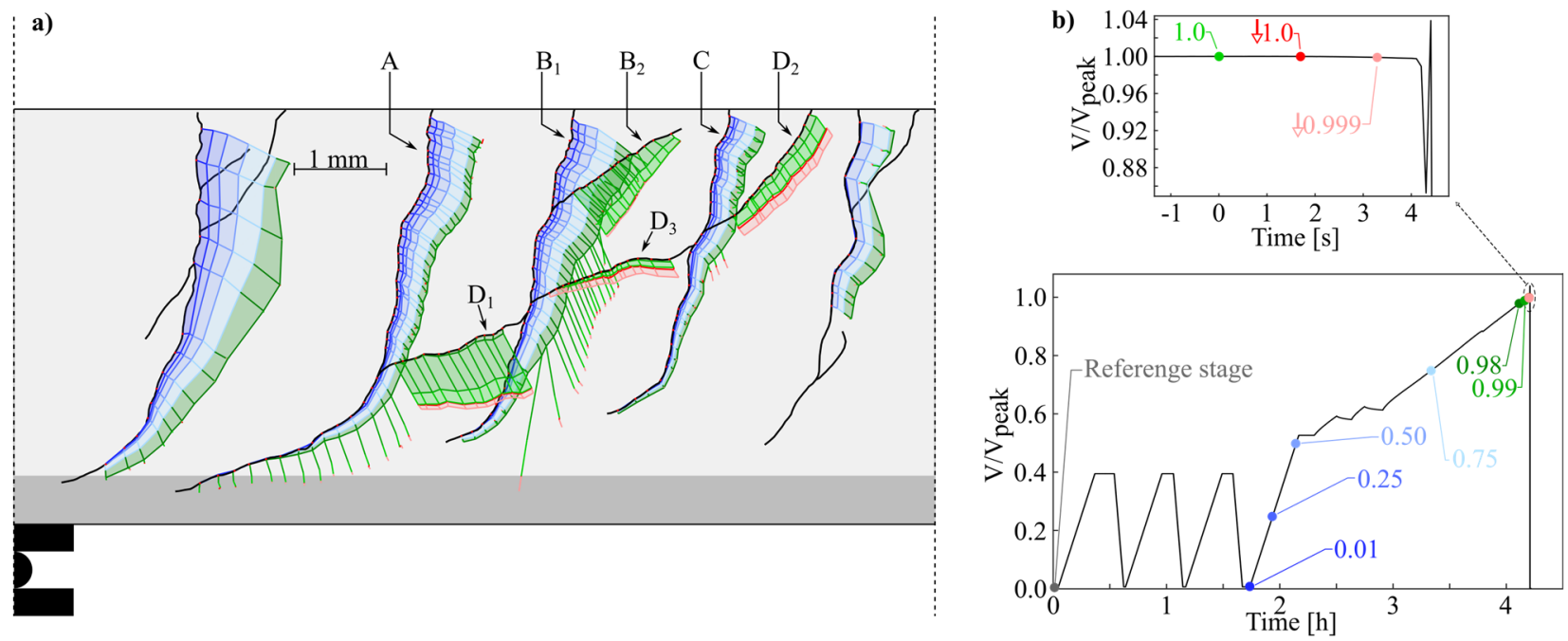

Figure 5. Merging of cracks: a) Crack propagation and relative crack displacement at selected load stages of specimen G3P40-1; b) Force-time diagram of the loading procedure. Each colored dot represent the selected load-stage for the relative crack displacement in plot (a. 
a)

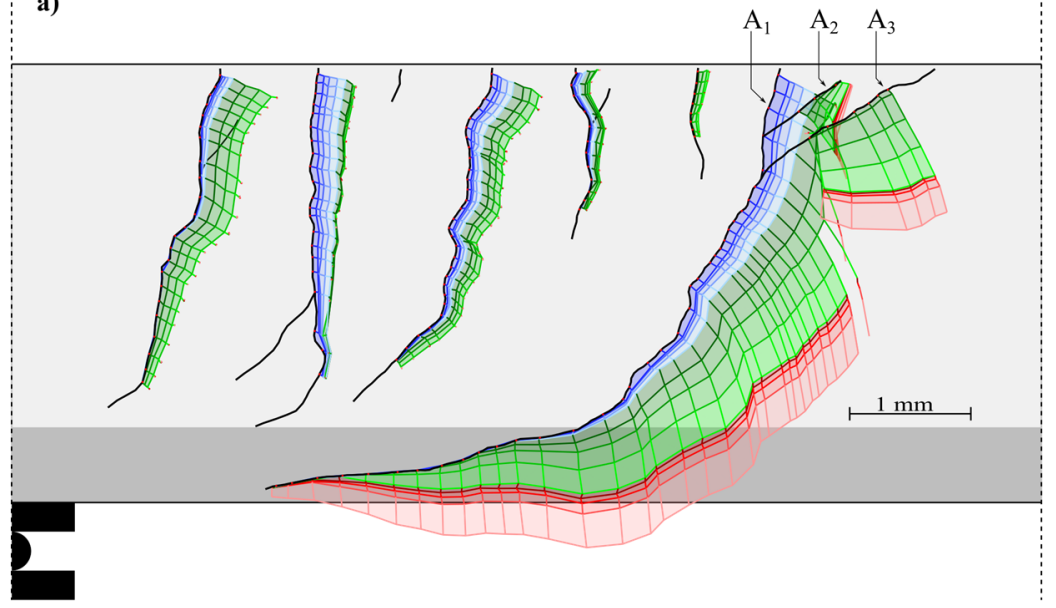

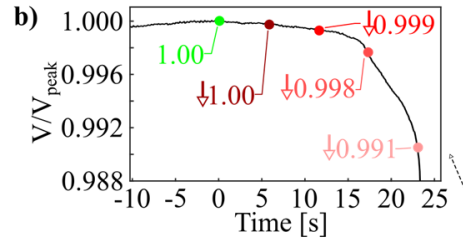

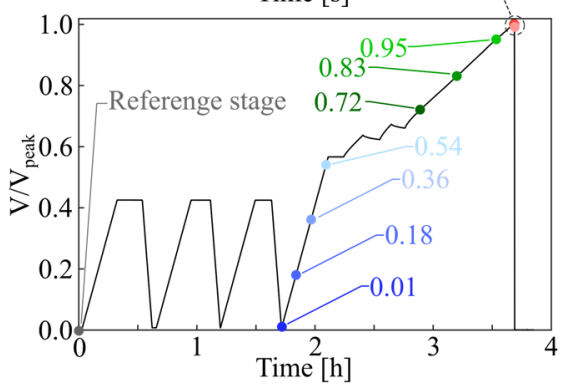

Figure 6. Single crack propagation: a) Crack propagation and relative crack displacement at selected load stages of specimen G3P30-2; b) Force-time diagram of the loading procedure. Each colored dot represent the selected load-stage for the relative crack displacement in plot (a.

Beam G3P40-1 and G3P30-2 were, however, somewhat atypical cases, where the mode of failure could be referred to as either merging of cracks or single crack propagation. In many instances, the cracking process triggering collapse was observed to be a mix of the two modes. This was the case with e.g. specimen G3P20-1, see Figure 4. Crack $B_{2}$ was developed from crack $B_{1}$ and joined with crack $A$ before reaching $0.95 \mathrm{~V} / \mathrm{V}_{\text {peak. }}$ Crack $\mathrm{B}_{3}$ were developed instantly after $B_{2}$ merged with crack $A$, whereupon all crack displacements were localized in the merged critical crack, which subsequently propagated as one. After reaching peak-load, an almost horizontal crack $\mathrm{B}_{4}$ becomes visible as the displacements in the critical crack were increased. Failure was initiated by merging of the cracks, but collapse occurred multiple load stages afterwards, where the critical crack had further propagated into the compressive zone, and with large crack displacements.

No apparent relation between the capacity and the failure mode were observed. Nor was any connection observed between the failure mode, the concrete strength or reinforcement ratio. However, as can be seen clearly in all three figures (Figures 4, 5, and 6) the crack displacements practically only occur in cracks associated with the failure line once the peak load has been reached. Simultaneously with the localization of the displacement in the critical crack, minor decreases of the crack displacement were observed in the surrounding non-critical cracks. A similar tendency is observed with the optical fibre measurements, where large strain increments are measured from a few stages before peak-load at the location of the critical crack, while a decrease of the strains in the surrounding parts of the concrete is observed. It should be noted that the loads are slightly decreased after reaching peak load, which might explain a minor part of the crack displacement and strain decrement.

\section{Centre of rotation of the specimen during failure}

Motivated by the aforementioned observation regarding displacement localization, an attempt was made in order to deduce the mode of deformation during failure. The deformations of the specimen, when close to collapse, are assumed to be caused by bending in combination with rigid body motion. The bending deformations, see Figure 7a, are due to reliefs of the elastic deformation of the beam following localization of the crack displacements in the critical cracks. The rigid body motions, on the other hand, are derived on the basis of the assumption that the failure line leads to a division of the beam into two rigid parts, rotating around certain points of rotation.

To this end, the displacement of ten points on each side of the critical crack between two stages after reaching peak-load, was measured and analysed. This approach was only possible for a few of the tested beams, as a certain magnitude of the displacement-increments between the two stages was needed in order to reduce the influence of noise on the one hand, and without the specimen collapsing on the other hand. The deformations due to the decrease of the applied load between the two stages were subtracted, e.g. if the load decreased by $2 \%$ of the peak-load between the two stages, the bending deformations the beam gained when loading from $10 \%$ to $12 \%$ of the peak-load were subtracted. This implies the assumption that the stiffness of the non-critical parts of the beam during unloading is identical to that during loading from $10 \%$.

Figure $7 \mathrm{~b}$ shows the results for the case of beam G2P25-1, and Figure 7d gives the location of the centre of rotations of all beams studied. As seen, the centre of rotation is in all cases close to the locations of the two supports, and this examination thus suggests that the relative displacements during failure can be adequately described by assuming the instantaneous centre of rotations to be located at the supports, as shown Figure 7c. 


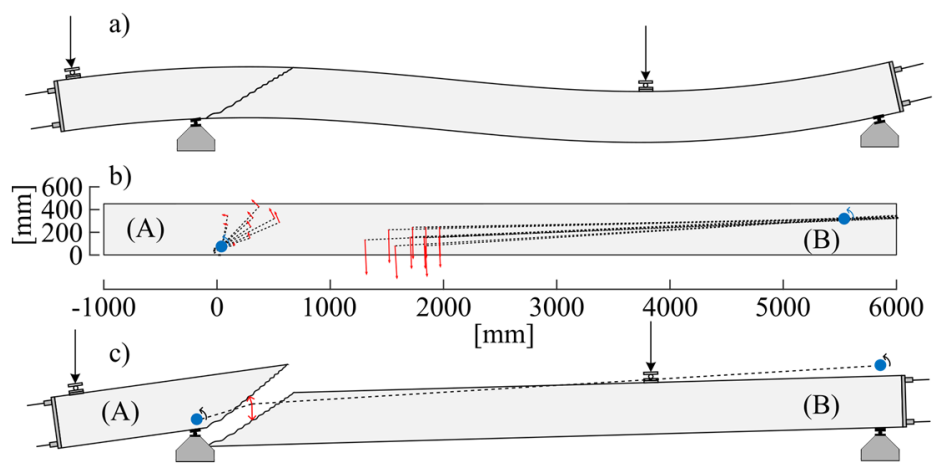

d)
\begin{tabular}{|c|c|c|c|c|}
\hline & \multicolumn{2}{|c|}{$\begin{array}{c}\text { Ridged bodies } \\
\text { centre of rotation (A) } \\
\text { [mm] }\end{array}$} & $\begin{array}{c}\text { Ridged bodies } \\
\text { centre of rotation(B) } \\
{[\mathbf{m m ]}}\end{array}$ \\
\hline & $\mathrm{X}$ & $\mathrm{Y}$ & $\mathrm{X}$ & $\mathrm{Y}$ \\
\hline G2P25-1 & 13 & 294 & 5310 & 1132 \\
\hline G2P25-2 & 6 & 152 & 6124 & 1223 \\
\hline G3P20-1 & 16 & 119 & 6789 & 128 \\
\hline G3P50-1 & -6 & 93 & 6279 & 385 \\
\hline G3P50-2 & 35 & 70 & 5539 & 315 \\
\hline
\end{tabular}

Figure 7. a) Elastic bending deformations of the specimen; b) Measured centre of rotation relatively between two stages after peak-load for G2P25-1; c) Rigid body deformations of the specimen; d) x- and y-coordinates for the center of rotation relatively between two stages after peak-load

\section{Crack surface}

To study the possible influence of the concrete strength in regards to the cracks surfaces, multiple cores were drilled from the failed specimens at the position of non-critical cracks. Four of the extracted samples are shown in Figure 8a), one for each concrete mix of the third group. The difference between the crack roughness of the different concrete groups were not obvious at first sight, as the crack did propagate both through and around aggregates in all four mixtures. Deeper studies showed that in the higher strength concrete, the crack would more frequently propagate through the aggregates, especially if the detour around the aggregates was considerable. Weaker aggregates, e.g. flint, are more frequently observed fractured in all concrete types.

The crack displacements of the critical crack at peak-load were further studied, and Figure 8b shows both the total crack displacement $(\delta)$, crack width $\left(\delta_{w}\right)$ and crack slip $\left(\delta_{s}\right)$ around peak-load. As seen, no clear tendency of larger admissible crack width at lower strength concrete is observed. Nor is there any tendency of larger crack slips at higher strength concrete due to larger slips needed in order for the further activating of aggregate interlock in combination with smoother crack surfaces. The same conclusions hold when examining additional measurement points within the body of the beam.
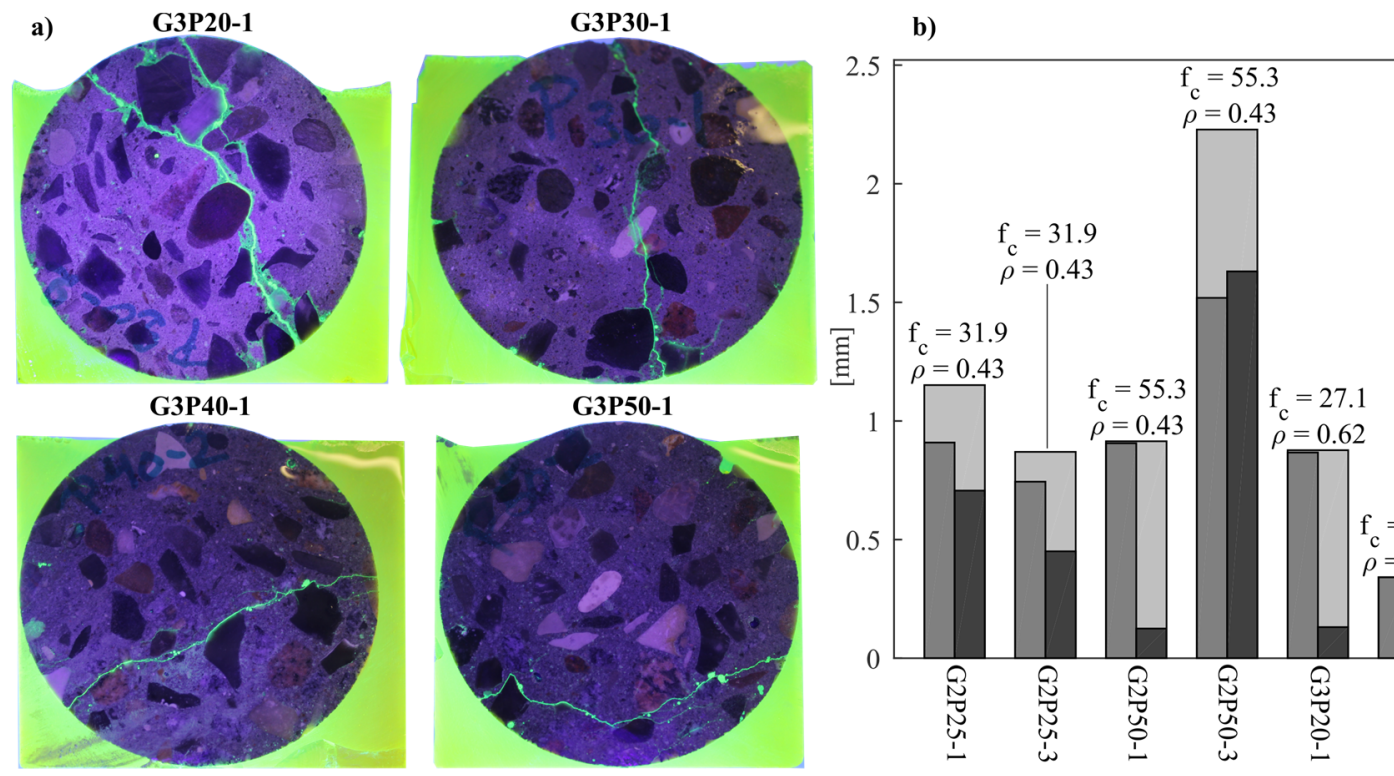

Figure 8. a) Epoxy samples of concrete cores extracted from failed specimens at non-critical cracks; b) Crack displacements of the critical crack around peak-load of selected specimens. The displacement where measured in the middle of the beam height

\section{Conclusions}

This experimental programme presents detailed measurements on cantilevered concrete members without transverse reinforcement, aimed at simulating the behaviour of concrete slabs in the hogging region of multi-span slabs. Besides overall results, the focus has been on the behaviour and crack development prior to and during the process of failure. On this basis, the following conclusions are made: 
- All beams failed in shear in a very brittle manner. It was practically impossible to predict the location of the critical crack before the actual collapse.

- Increasing the compressive strength of the concrete led to a gradual improvement of the shear capacity. However, for a concrete strength beyond $58.1 \mathrm{MPa}$, a consistent and significant drop in regards to the shear capacity was observed.

- Increasing the longitudinal reinforcement ratio had little or no influence on the resulting shear capacity.

- All tested beams exhibited practically similar cracking-behaviour prior to peak load irrespectively of the actual concrete strength and longitudinal reinforcement ratio.

- Two different modes of crack propagation governed the development of the critical cracks and failure line during the process of failure. There was no apparent influence of neither the concrete strength nor the longitudinal reinforcement ratio in regards to the observed mode of failure.

- All crack displacements during the process of failure were localized only in the critical cracks. The corresponding relative displacements can be adequately accounted for on the basis of simple rigid body displacements.

- The influence of the concrete compressive strength on the crack surface and the crack displacements of the critical crack around peak-load was not observed very pronounced. A minor tendency indicated that with higher strength concrete, the crack would more frequently propagate through the aggregates.

\section{Acknowledgements}

Olling N., Svarre C., and Vistisen A. J. as part of their Master's Thesis performed the experimental work presented in this paper. The authors would like to acknowledge both the financial support of the COWIfonden and the sponsorship of the high strength reinforcement by SAH (Stahlwerk Annahütte).

\section{References}

Angelakos, A., Bentz, E. C., \& Collins, M. P. (2001). Effect of concrete strength and minimum stirrups on shear strength of large members. ACI Structural Journal, 98(3), 290-300. https://doi.org/10.14359/10220

Collins, M. P., Bentz, E. C., \& Sherwood, E. G. (2008). Where is shear reinforcement required? Review of research results and design procedures. ACI Structural Journal, 105(5), 590-600. https://doi.org/10.14359/19942

Leonhardt, F., \& Walther, R. (1962). Schubversuche an einfeldrigen Stahlbetonbalken mit und ohne Schubbewehrung. Deutscher Ausschuss für Stahlbeton, 151, 83.

Olling, N., \& Svarre, C. (2017). Observations and considerations on shear failure in cantilevered concrete slab strips without transverse reinforcement (Master's Thesis). Aarhus University.

Pedersen, J. G., Fisker, J., \& Nielsen, C. B. (2015). Nonlinear finite element analysis of non-shear reinforced concrete beams. Concrete - Innovation and Design: fib Symposium Proceedings. Federation international du beton (fib), s. 432-433, FIB Symposium 2015. Copenhagen, Danmark, 18/01/15.

Podgorniak-Stanik, B. A. (1998). The influence of concrete strength, distribution of longitudinal reinforcement, amount of transverse reinforcement and member size on shear strength of reinforced concrete members (Master's thesis). University of Toronto.

Reineck, K.-H., Kuchma, D. A., Kim, K. S., \& Marx, S. (2003). Shear database for reinforced concrete members without shear reinforcement. ACI Structural Journal, 100(2), 240-249. https://doi.org/10.14359/12488

Sherwood, E. (2008). One-way shear behaviour of large, lightly-reinforced concrete beams and slabs. University of Toronto, Department of Civil Engineering.

Walraven, J. C., \& Stroband, J. (1994). Shear friction in high-strength concrete. ACI Special Publication, 149, 311-330. 